
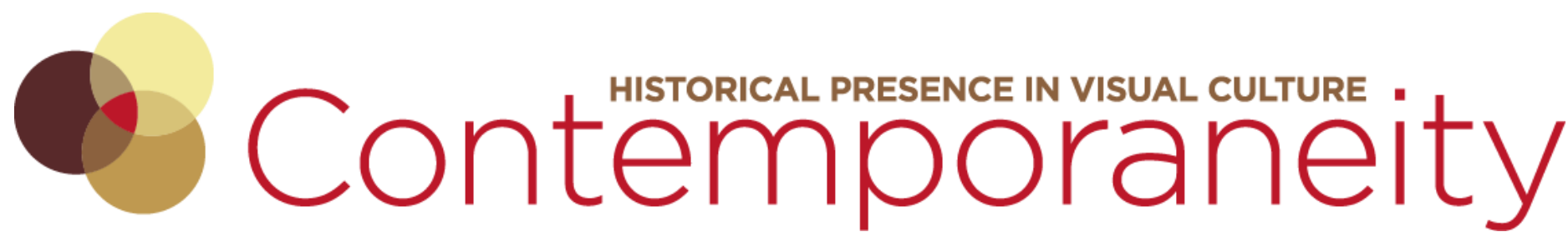

Vol 6, No 1 "Boundless" (2017) | ISSN 2153-5914 (online) | DOI 10.5195/contemp.2017.223

http://contemporaneity.pitt.edu

\title{
Untitled (Architectural Photography)
}

Daniel Pabst

\section{About the Artist}

Daniel Pabst was born in 1971 in Vienna. He began working as a photographer at his father's gallery, Galerie Michael Pabst, in Munich. He has shown work at PhotoMonth London (2015); photo: vienna at the Museum of Applied Arts Vienna (2015), EyeEm-Awards in New York City (2015); Lange Nacht der Museen in Klagenfurt, Austria (2014); in der Kubatur des Kabinetts, der Kunstsalon im Fluc, Vienna, among others. As an EyeEm Award Finalist in 2015, Pabst's work was shown among the Top 10 for the category "The Architect," accordingly exhibited in New York City. Pabst received honorable mentions for the Moscow International Foto Award (MIFA) in 2015 and for the Tokyo International Foto Award (TIFA) in 2016.

Pabst also studies jazz guitar and jazz composition. He is the singer and songwriter of PABST. Additional bands in which Pabst participated were Noisy Town Groove, with drummer and composer Lukas Ligeti, Trafo (an electric guitar quartet), and Tricsson, an electronica band. Pabst has also collaborated with Dezibel 6 to 6 string and Bella Angora, a performance artist (production for the Donaufestival 2013). He works as the producer and founder of the record label 212 RecordsPabst and co-composed the opera "der automatische Teufel," with Jury Everhartz. He has performed concerts for twenty years in Europe and the United States at venues such as the Wiener Konzerthaus, Porgy and Bess, Austrian Cultural Forum NYC, The Stone, Ancienne Bélgique in Brussels, b-flat in Berlin, among others. 



\section{Untitled \\ (Architectural Photography)}

\section{Daniel Pabst}

Daniel Pabst's architectural photography often highlights the tension between site-specificity and the legacy of early twentieth-century international style. In photographs of diverse sites across the globe, such as Dallas, Texas, St. Petersburg, Russia, and Vienna, Austria, Pabst draws attention to the formal qualities of such architecture hailed for its ability to communicate internationally but inherently tied to particular locations-as reflected in Pabst's titular conventions. As such, his photographs of buildings, whose functions range from public offices to private residences, and everything between, reveal moments where placeless meets place.

Rae Di Cicco

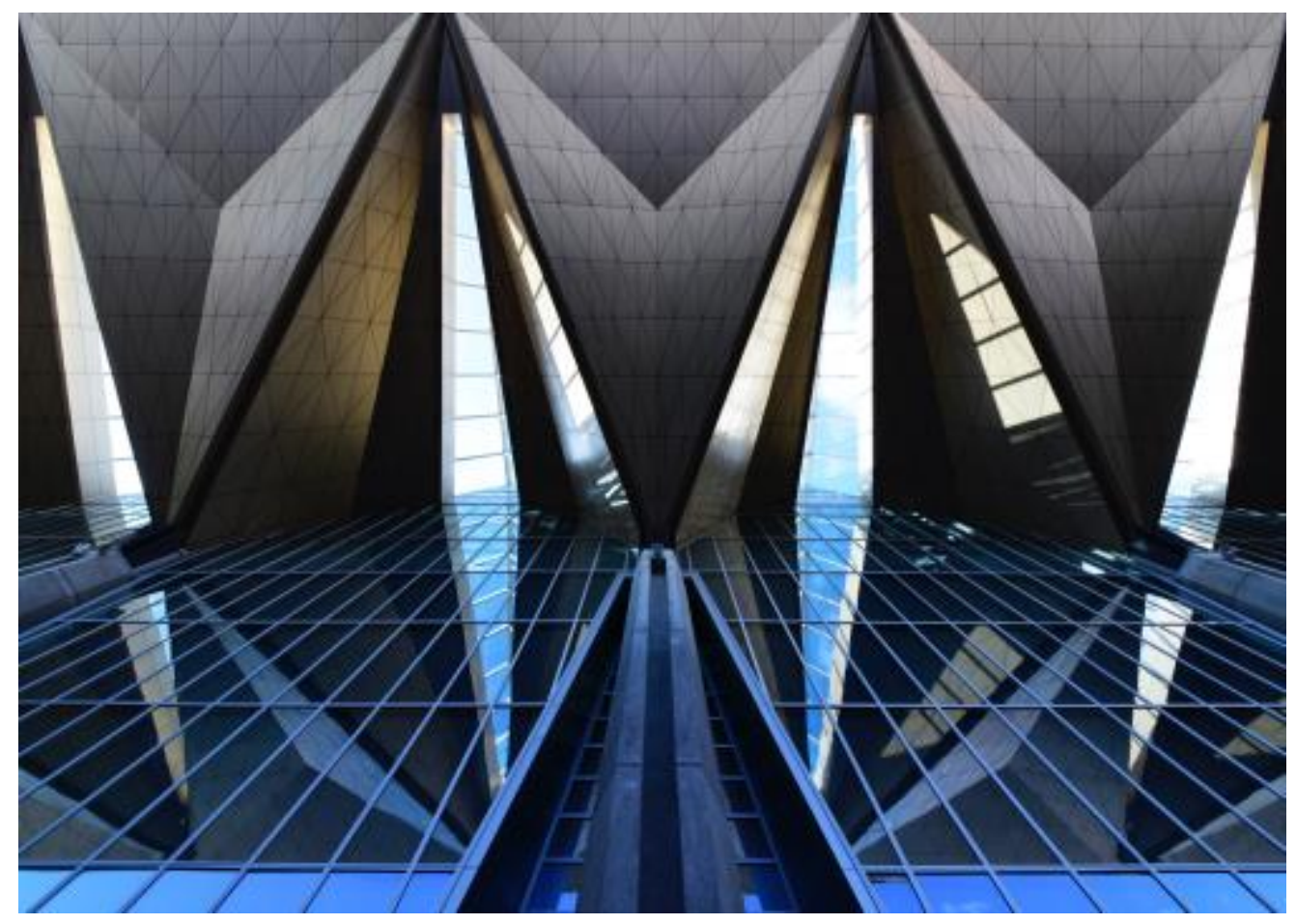

Figure 1

Daniel Pabst, Pulkovo Airport (Saint Petersburg), 2015, digital photograph. 


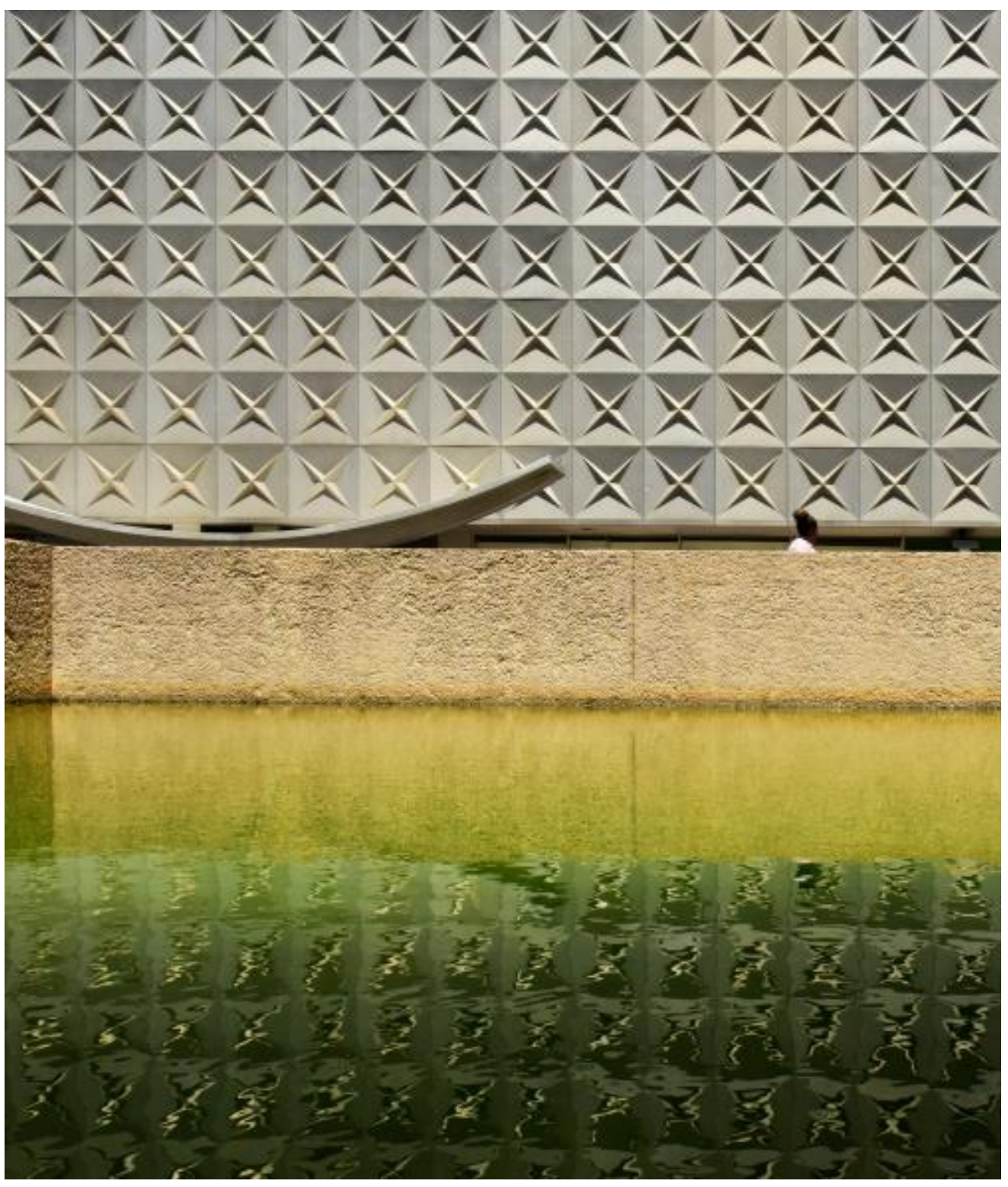

Figure 2

Daniel Pabst, Gables Republic Tower Dallas, 2016, digital photograph. 


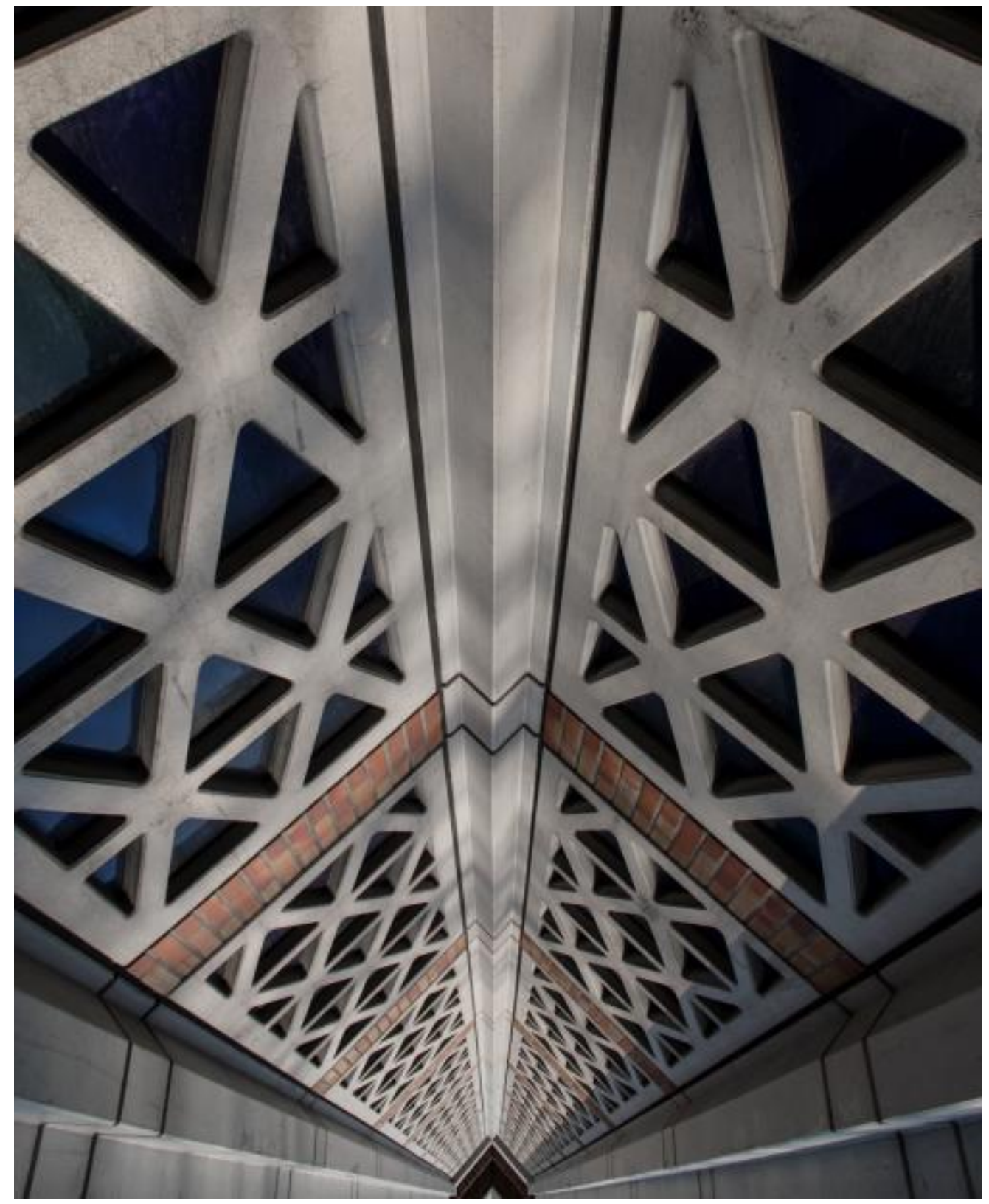

Figure 3

Daniel Pabst, Public Office for Finance Vienna, 2015, digital photograph. 


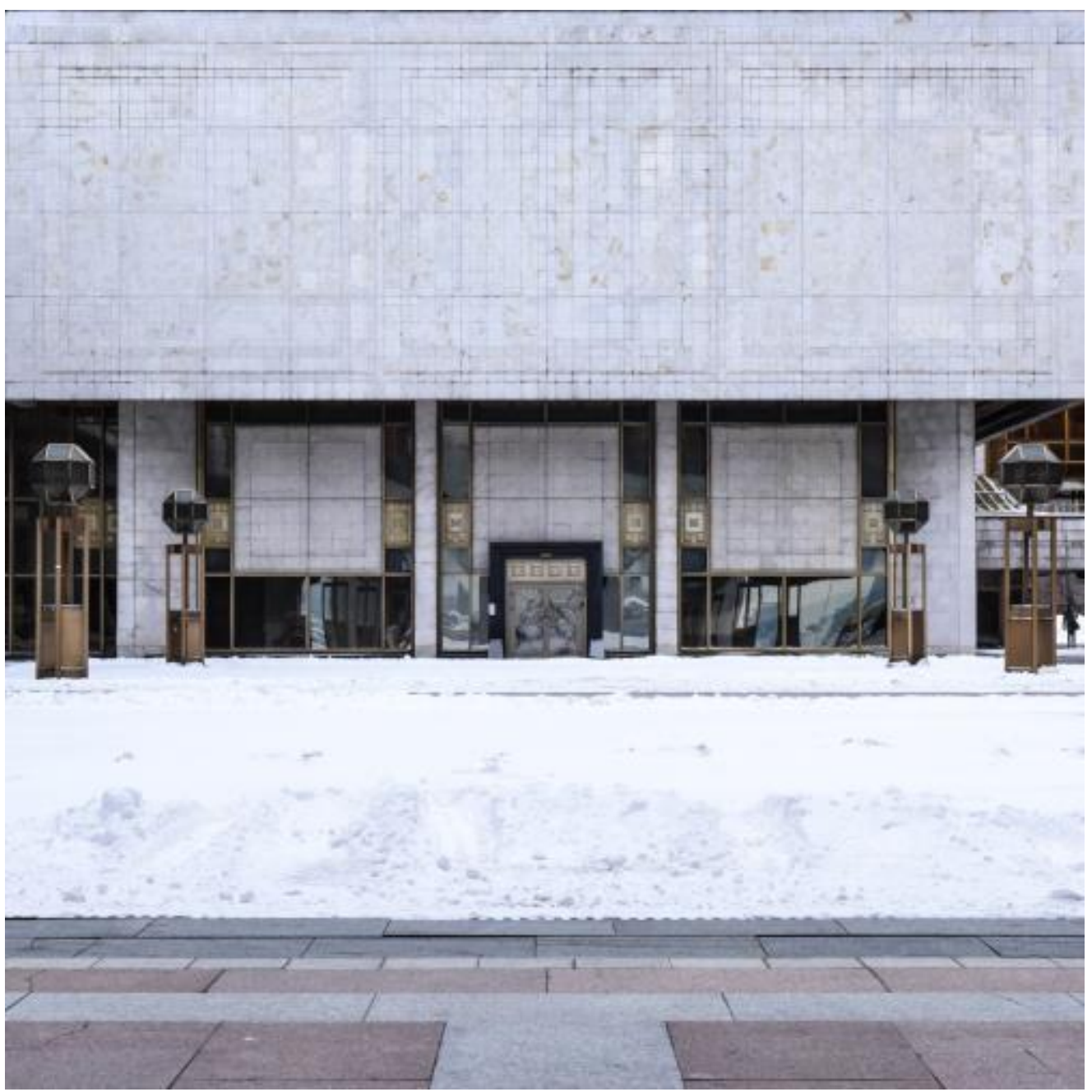

Figure 4

Daniel Pabst, Academy of Sciences Moscow, 2017, digital photograph.

\section{(cc) $\mathrm{BY}$} Attribution 4.0 United States License.

\section{ULIS D-Sonle}

This journal is operated by the University Library System of the University of Pittsburgh as part of its D-Scribe Digital Publishing Program, and is co-sponsored by the University of Pittsburgh Press. 